\title{
Scanning electron microscopic studies on the methane hydrate decomposition using the freeze-fracture replica method
}

\author{
Ayumi FUJIMOTO ${ }^{1}$ and Takeshi SUGAHARA ${ }^{2 *}$ \\ 1 Kaneka Techno Research Corporation, Settsu, Osaka 566-0072, Japan \\ 2 Division of Chemical Engineering, Graduate School of Engineering Science, Osaka University, Toyonaka, Osaka 560-8531, Japan \\ *sugahara@cheng.es.osaka-u.ac.jp
}

(Received October 20, 2017; Revised manuscript accepted November 28, 2017)

\begin{abstract}
It is well known that methane hydrate exhibits abnormal stability, so-called "self-preservation effect" at temperatures of $240 \mathrm{~K}$ to $270 \mathrm{~K}$ and atmospheric pressure, though the equilibrium temperature of methane hydrate at atmospheric pressure is approximately $190 \mathrm{~K}$. The ice shielding at the surface of methane hydrate would be one of the most important steps toward developing the self-preservation. That is, to observe the phase and morphology changes from methane hydrate to ice is significant. We have observed the microstructural change of the synthetic methane hydrate during its decomposition at the temperatures of $263 \mathrm{~K}$ and $293 \mathrm{~K}$ with a combination of scanning electron microscopy (SEM) and the freeze-fracture replica method. The SEM images reveal that the methane hydrate crystal has a structure arranging the clusters of $20 \mathrm{~nm}$ in diameter. When the methane hydrate is partially decomposed during taken from the high-pressure cell (rapid depressurization at $253 \mathrm{~K}$ ), a part of the clusters changes to the cluster aggregates of $60-200 \mathrm{~nm}$. The cluster aggregates gradually grow from their peripheries to the hexagonal ice crystals during gradual decomposition at $263 \mathrm{~K}$. The microstructural change supports the decomposition mechanism of methane hydrate by ice-shielding under a temperature condition with self-preservation effect. At $293 \mathrm{~K}$, the methane hydrate is immediately decomposed. The residual aqueous solution after complete decomposition contains the large number of ultrafine bubbles (nanobubbles) of $100 \mathrm{~nm}$ or less in diameter.
\end{abstract}

Key words: gas hydrate, ice, self-preservation, SEM, freeze-fracture replica method, ultrafine bubble

\section{Introduction}

Gas hydrate or clathrate hydrate, a kind of inclusion compounds, is stabilized by guest species in the cavity of hydrogen-bonded water cages (Sloan and Koh, 2008). In the methane hydrate, the methane molecules are enclathrated as the guest molecules in two kinds of cavities. Methane hydrate has become the object of much attention because enormous quantities of natural gas in the form of gas hydrate exist in the permafrost regions and the sediments under the deep-ocean floor. A significant characteristic of gas hydrates is relatively large gas storage capacity. Therefore, methane hydrate has been proposed as a storage and transportation medium of natural gas (Gudmundsson and Børrehaug, 1996; Shirota et al., 2002; Takaoki et al., 2002; Rehder et al., 2012). To keep a gas hydrate form, generally speaking, gas hydrate must be stored or transported in a pressuretemperature condition where gas hydrate is thermodynamically stable. Yakushev and Istomin (1992) reported unexpected high stability of methane hydrate at
$0.1 \mathrm{MPa}$ and a temperature below $273 \mathrm{~K}$ which is under a non-equilibrium condition (Falabella and Vanpee, 1974; Makogon and Sloan, 1994). Yakushev and Istomin (1992) called the effect as "gas-hydrates self-preservation effect". After that, Stern et al. (2001) reported anomalous preservation of methane hydrate at isothermal conditions between 242 and $271 \mathrm{~K}$. Many researchers have investigated the self-preservation effect with kinetics and spectroscopic approaches (Falenty et al., 2014; Kuhs et al., 2004; Mel'nikov et al., 2003; Melnikov et al., 2009; Ohno et al., 2011; Sato et al., 2009, 2013; Takeya et al., 2005; Takeya and Ripmeester, 2008; Takeya et al., 2001, 2011; Uchida et al., 2011 b; Zhong et al., 2016). Their vigorous investigations have revealed that the self-preservation depends on the temperature, guest molecules, and pressure. The temperature dependence is derived from the ice nucleation and shielding and the existence of (supercooled) aqueous solutions, according to the literature mentioned above. The ice nucleation from water released by gas hydrate decomposition exhibits very complicated behavior (Kuhs et al., 2004).

Murakami et al. (1997) reported the preparation of 
the replica film using mixed hydrocarbon plasma for fieldemission scanning electron microscopy (SEM) observation. They adopted a $\mathrm{CO}_{2}$ hydrate under decomposition as a sample to show the availability of the freeze-fracture replica method. They reported the existence of ultrafine bubbles released at the surface of $\mathrm{CO}_{2}$ hydrate and the aggregates of 50-100 nm (they claimed gas aggregates, but we speculate the gas hydrate aggregates, not gas aggregates). Kuhs et al. (2000, 2004), Falenty et al. (2007, 2014), and Rehder et al. (2012) have observed the microstructural changes of gas hydrate formation from ice and back by means of cryo-SEM on a $100 \mathrm{~nm}$-scale under $10 \mathrm{~nm}$ resolution limit. They have reported ice nucleation behavior at various temperatures and proposed the mechanism of the self-preservation effect. We believe the microstructural change occurs on a scale smaller than $100 \mathrm{~nm}$, based on the literature on the nucleation behavior of many kinds of crystals (Hirokawa et al., 1994; Ishizuka et al., 2017; Machida et al., 2017; Murakami et al., 1997; Ohgaki et al., 1991, 1992; Ueda et al., 1995; Yamazaki et al., 2017). In the present study, we observed the microstructural changes in the decomposition processes of a synthetic methane hydrate on a $10 \mathrm{~nm}$-scale by means of SEM with freeze-fracture replica method.

\section{Experimental}

\subsection{Freeze-fracture replica method}

Freeze-fracture replica method (Ohgaki et al., 1991; Hirokawa et al., 1994; Murakami et al., 1997; Fujimoto, 2017) was used as a method for observing the microstructures of the methane hydrate crystal and the aqueous solution after its complete decomposition. A sample (hydrates or aqueous solution) was dipped into liquid 2-methylbutane (isopentane, Wako) at its melting point (113 K). The quenched and vitrified sample was set in a vacuum chamber (JEOL, EM-19501 JFD-V) precooled at cryogenic temperatures of approximately $80 \mathrm{~K}$. In general, soon after cutting the vitrified sample inside the chamber under vacuum of $10^{-5} \mathrm{~Pa}$ and $80 \mathrm{~K}$, the carbon is vapor-deposited to the resulting cut surface to prepare a replica film. After removing the sample from the replica film (the thickness was estimated to be approximately 4 $\mathrm{nm}$ ), it was picked up on a 200-mesh copper grid (VECO, square type). The surface morphology of a slightly inner parts from the perimeter of the replica film was observed by SEM (Carl Zeiss, ULTRAplus, acceleration voltage: $2 \mathrm{kV}$, detector: InLens). The original resolution of SEM is approximately $1 \mathrm{~nm}$, but, considering the particle size of deposited carbon, the overall resolution limit of SEM images observed in the present study is a couple of nanometers.

\subsection{Preparation of samples}

In the present study, we observed the replica films derived from three samples: methane hydrate
(sample“A”), partially-decomposed methane hydrate at $263 \mathrm{~K}$ ("B"), and residual aqueous solution after complete decomposition of methane hydrate at $293 \mathrm{~K}$ ("C"). The pressure-temperature history that methane hydrate experienced and the relation of three samples with the phase diagram of methane hydrate are shown in Fig. 1.

Methane hydrate was prepared in a high-pressure cell with internal mixing bar (driven by a permanent magnet ring) vertically moving across the gas-liquid interface. The cell was essentially the same to that reported previously (Sugahara et al., 2003). The highpressure cell has a water jacket to maintain the cell temperature at $280 \mathrm{~K}$ by circulating thermostatic water. Distilled water (Wako) was introduced into the cell and then pressurized with methane at a pressure up to 6.0 $\mathrm{MPa}$, which is slightly higher than the three-phase (gas, aqueous, and hydrate phases) equilibrium pressure of methane hydrate at $280 \mathrm{~K}$. Mixing was started, and the methane hydrate was formed after an induction period. The pressure was regulated at $6.0 \pm 0.2 \mathrm{MPa}$ by intermittently supplying methane because methane was gradually consumed as methane hydrate was formed. When the consumption of methane had almost ceased, the residual aqueous solution was drained through the needle valve of the bottom of the cell. During this period, the cell pressure was also regulated at $6.0 \pm 0.2 \mathrm{MPa}$. The remaining contents in the cell were kept at the same pressure for almost 5 days to convert the unreacted water to methane hydrate at the grain boundary region and then cooled with the high-pressure cell to $253 \mathrm{~K}$ for 1 day. The prepared methane hydrate was allowed to be depressurized to the atmospheric pressure at $253 \mathrm{~K}$ in a cold room. The obtained methane hydrate was quickly quenched and stored in a vessel at $77 \mathrm{~K}$. Some of

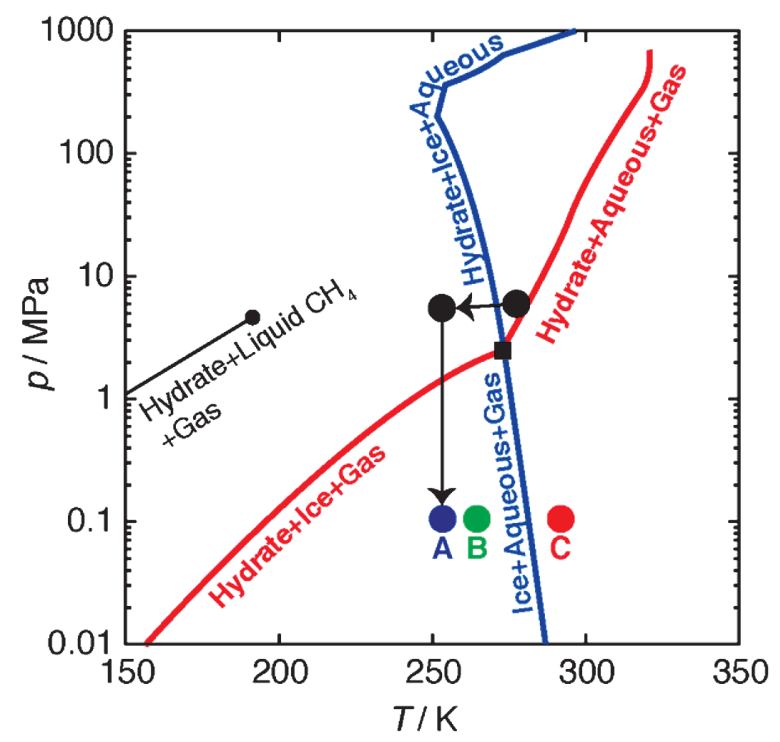

Fig. 1. Schematic phase diagram of methane hydrate. The arrows represent the pressure-temperature history methane hydrate experienced. The points A, B, and C stand for the sample collecting points for freeze-fracture replica method. 
translucent hydrate crystals were used for the replica film preparation as the methane hydrate samples without any change (Sample "A"). As a result of gas release measurement of the quenched hydrate samples, the hydrate ratio in the hydrate samples was approximately $70 \pm 10 \mathrm{~mol} \%$ and $20-30 \mathrm{~mol} \%$ of water contained as unreacted water (or methane was partially released from the hydrate sample until quenching after depressurization at $253 \mathrm{~K})$.

To observe the morphological change of methane hydrate during decomposition below $273 \mathrm{~K}$, some of translucent methane hydrate crystals were put into the freezer and allowed to be partially decomposed at $263 \mathrm{~K}$ for 2 hours. After taken from the freezer, the samples were quickly quenched with liquid 2-methylbutane at 113 $\mathrm{K}$ and then used for the replica film preparation (Sample“B"). Sato et al. (2009) reported that, when the initial hydrate ratio was a standard (100\%), approximately $15 \%$ of methane hydrate (prepared in almost the same manner as the present study) decomposed at $263 \mathrm{~K}$ for 10 hours. The hydrate ratio of the partially-decomposed hydrate at $263 \mathrm{~K}$ for 2 hours in the present study was estimated to be at least $60 \pm 10 \mathrm{~mol} \%$, that is, approximately $10 \mathrm{~mol} \%$ hydrate should be converted to ice at a maximum. To prepare the residual aqueous solution after complete methane hydrate decomposition, the crushed methane hydrate crystals were put on a hot stage at $293 \mathrm{~K}$ for $5 \mathrm{~min}$. The hydrates were completely decomposed in a few minutes. Droplets of the obtained aqueous solution were quickly quenched with liquid 2-methylbutane at $113 \mathrm{~K}$ and then used for the replica film preparation (Sample“C”).

\section{Results and Discussion}

Figure 2 shows the SEM images of the replica films reflecting the internal microstructure of methane hydrate crystals without any change after quenched (sample“A”). The images have two types of aspect: one is the clusters of approximately $20 \mathrm{~nm}$ in diameter; the other is the cluster aggregates with a size of 60-200 $\mathrm{nm}$ in diameter. The $20 \mathrm{~nm}$ clusters are dominantly included in the sample "A" and methane hydrate crystal composes of densely-packed clusters as shown in the bottom of Fig. 2. The minimum cluster size of $20 \mathrm{~nm}$ in a methane hydrate crystal agrees well with that in a citric acid monohydrate crystal (Ohgaki et al., 1991; Ohgaki et al., 1992), a $\mathrm{CO}_{2}$ hydrate (during decomposition) (Murakami et al., 1997), and a sodium acetate trihydrate crystal (Machida et al., 2017). Kuhs et al. (2000) reported that the bulk of methane hydrate was porous on a submicron scale of 100-400 nm on the basis of a cryo field-emission SEM observation. They could have observed only the aggregates, because they stated the $10 \mathrm{~nm}$ resolution limit of their setup. The cluster aggregates of 60-200 nm, consisting of the $20 \mathrm{~nm}$ clusters, resemble the "clustercysts" in the crystallization
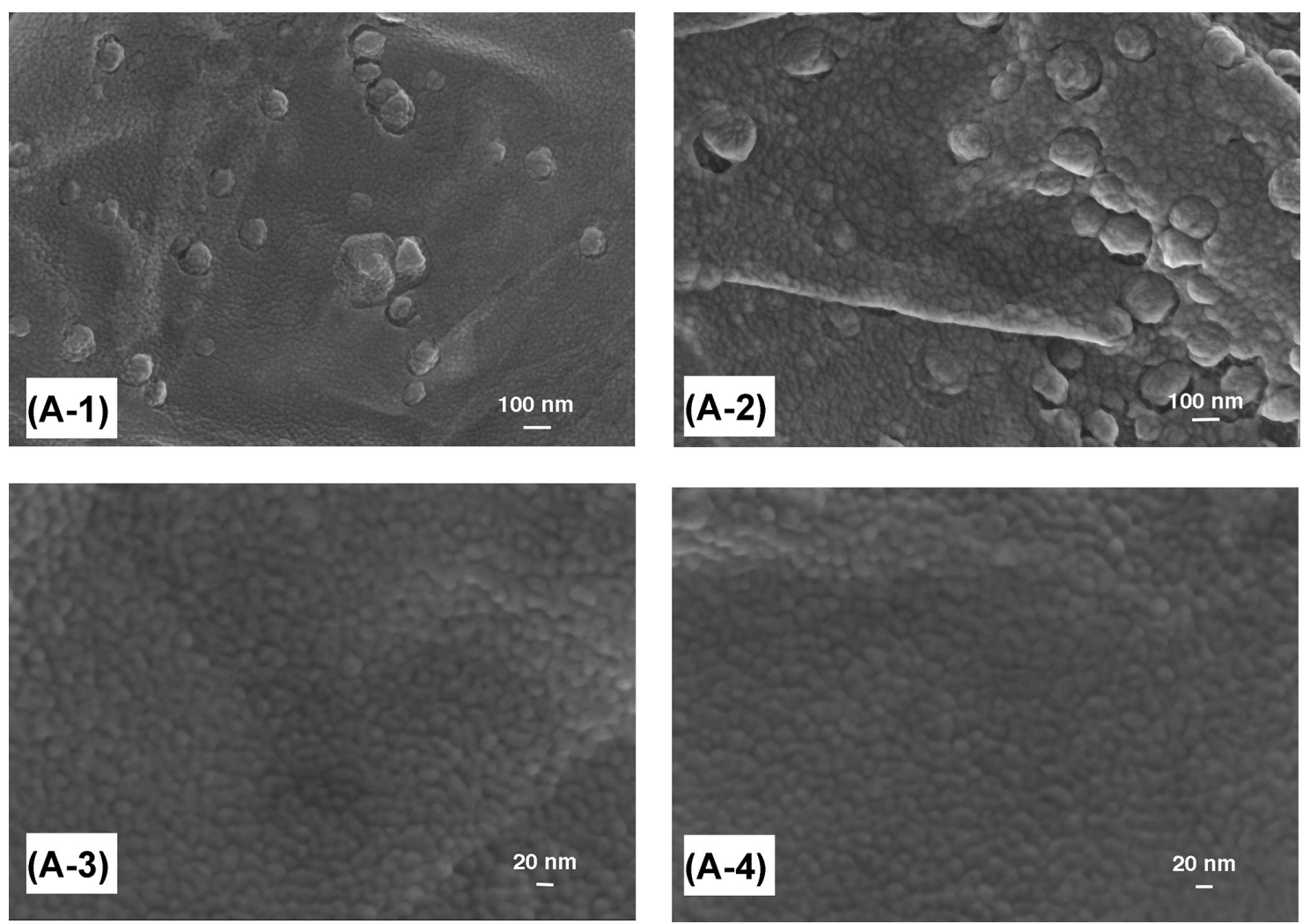

Fig. 2. SEM images of the replica films reflecting the internal microstructure of synthetic methane hydrate just after taken out from the high-pressure cell (Sample "A"). The images are derived from different hydrate crystals at 50 thousands-fold (upper) and 150 thousands-fold (lower) magnifications. 
mechanism of a citric acid monohydrate crystal reported by Ueda et al. (1995). Unlike a citric acid monohydrate crystal, however, the methane hydrate dominantly consists of the $20 \mathrm{~nm}$ clusters. The aggregates seem to be different from the clustercysts as discussed in the next paragraph.

As the methane hydrates were partially decomposed at $263 \mathrm{~K}$ for 2 hours (Sample “B”), the internal microstructure near the surface of the sample, where methane hydrate slowly decomposes, was drastically changed from that of the methane hydrate before decomposition (Sample“A”). As shown in Fig. 3, the cluster aggregates of 60-200 nm in diameter, which have a similar size to those included in the methane hydrate before decomposition (Fig. 2), were scattered. In addition to the spherical aggregates, the SEM images of the sample"B" contained the facets of hexagonal ice Ih that began growing from the periphery of the aggregates. Mimachi et al. (2015) have reported that the periphery of the thermal or mechanical cracks in a synthetic naturalgas hydrate tends to be a dissociation site. The ice formation behavior around the 60-200 nm aggregates implies that the cluster aggregates observed in Fig. 2 resulted from the partially decomposition of methane hydrate when the hydrate sample was taken from the high-pressure cell at $253 \mathrm{~K}$.

The surrounding of the aggregates in Fig. 3 was relatively smooth, while that in Fig. 2 was filled with the clusters of $20 \mathrm{~nm}$. The smooth zone in Fig. 3 implies the surface resulting from ice shielding (Uchida et al., 2011b) at the surface of clusters. Falenty et al. (2014) reported the SEM images (micrometer scale) of similar smooth surface observed at $260 \mathrm{~K}$ and $0.1 \mathrm{MPa}$. The smooth surface might imply the existence of mobile supercooled water suggested by Takeya et al. (2005), Mel'nikov et al. (2003), Melnikov et al. (2009), and Ohno et al. (2011). The ice-shielding would be supported by the existence of many holes (enlarged images around the holes are shown in Fig. 4) through which methane should be released from the inside of the sample. The fluid methane enveloped by ice shielding might be released in the fracture operation. The existence of many holes was observed by Falenty $e$ t al. (2014). Takeya et al. (2011) reported that the average thickness of ice layer at the surface of a synthetic methane hydrate pellets stored at $253 \mathrm{~K}$ for a day was approximately $100 \mu \mathrm{m}$. In the present study, ice layer formed at $263 \mathrm{~K}$ for 2 hours seems to be thinner than 100 $\mathrm{nm}$ because the asperities derived from residual clusters in the smoothed zone were still observable. Such thinner layer would be due to different experimental conditions of holding temperature and duration.

Figure 5 shows the SEM images of the replica films reflecting the internal microstructure of aqueous solutions after methane hydrate completely decomposed at $293 \mathrm{~K}$. A number of ultrafine bubbles of $50-100 \mathrm{~nm}$ in diameter were observed. As long as the SEM images are seen, the
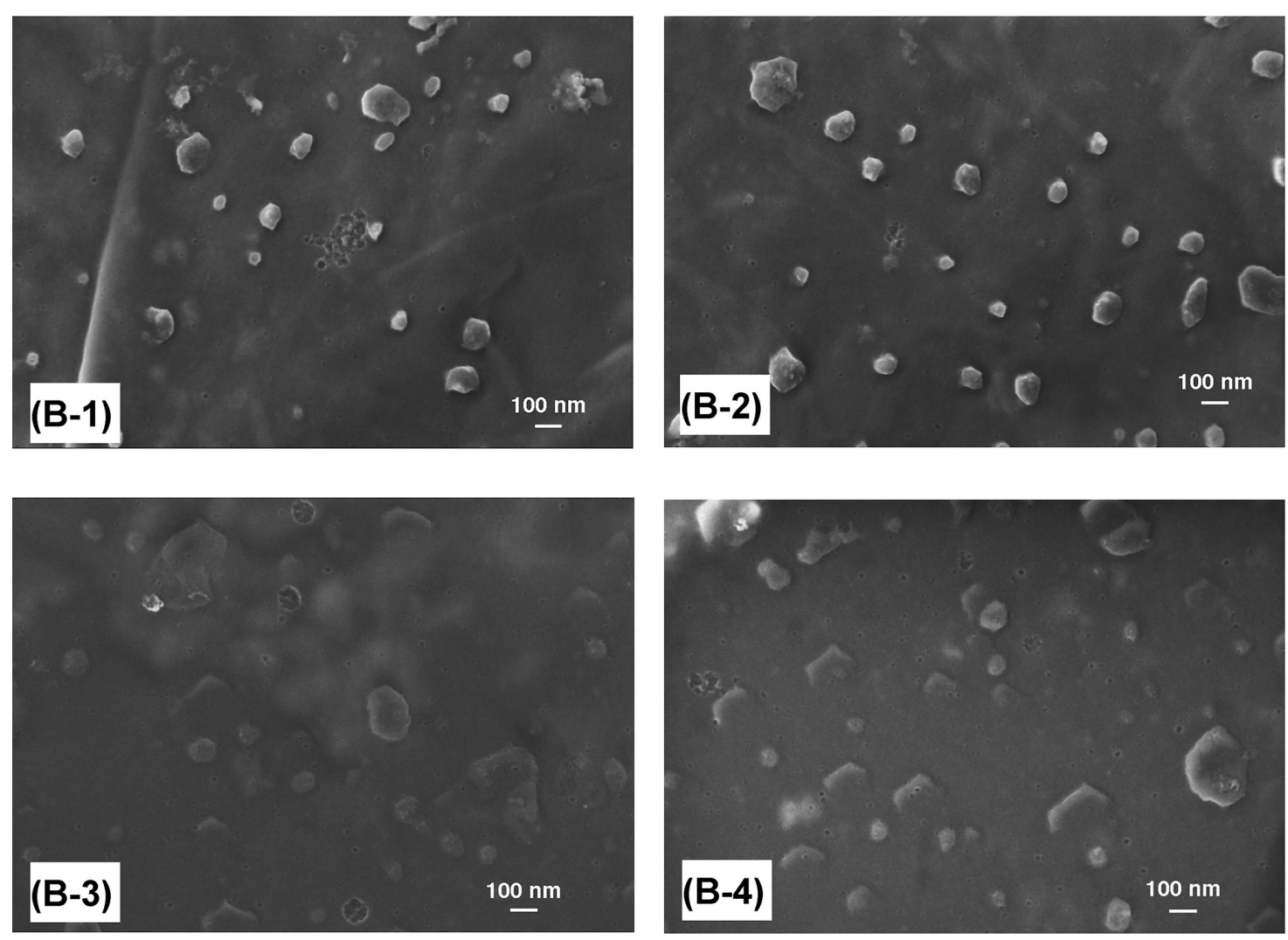

Fig. 3. SEM images of the replica films reflecting the internal microstructure of methane hydrate partially decomposed at $263 \mathrm{~K}$ for 2 hours (Sample "B"). 

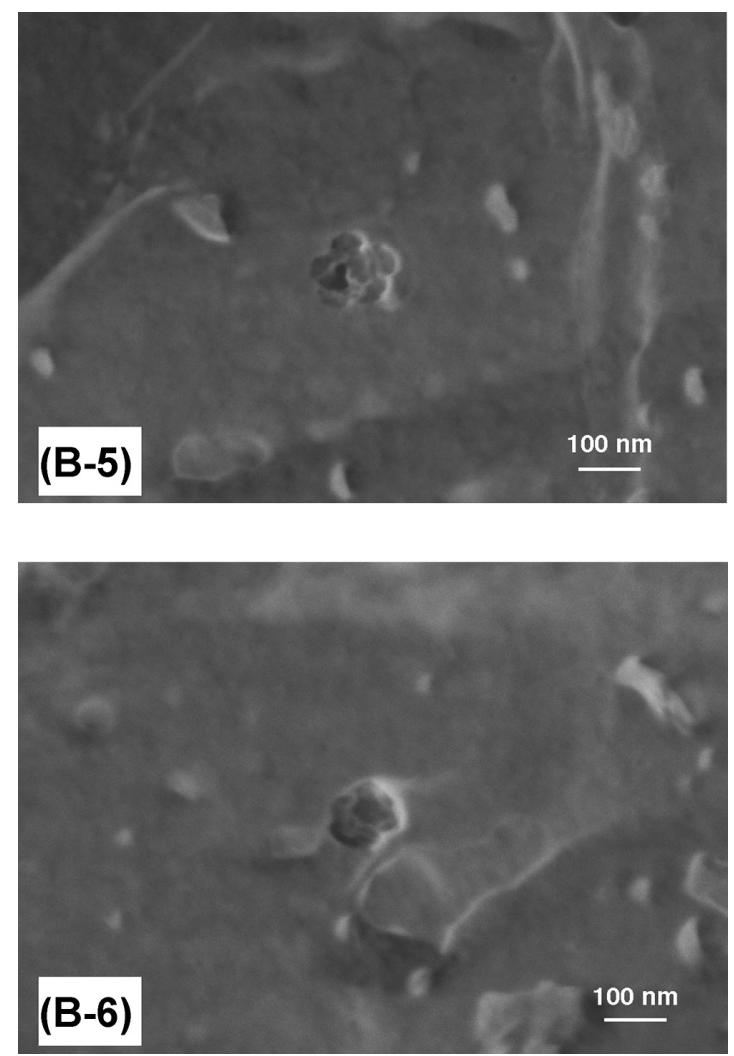

Fig. 4. Enlarged images around the holes in Fig. 3.

size distribution seems to be narrow. It has been already reported that the ultrafine bubbles contain in the aqueous solution resulting from gas hydrate decomposition (Uchida et al., 2016a). The bubble size is quite similar to that reported by Ohgaki et al. (2010) and smaller than that by Uchida et al. (2011a, 2016a, 2016b). The difference of the bubble size would be derived from how ultrafine bubbles were generated, especially in the case of "gas hydrate decomposition" method, how hydrate sample decomposed. The surface of bulk ultrafine bubbles is still subject to debate. The further investigation is needed to elucidate the bubble size and surface. The ultrasonic measurement recently reported by Leroy and Norisuye (2016) has been expected as a method to solve them simultaneously.

\section{Summary}

We observed the microstructural changes on a 10 nm-scale during the decomposition of a synthetic methane hydrate by means of SEM with freeze-fracture replica method. The mechanism of the self-preservation effect is very complicated and entangled with that of ice nucleation and growth. On the whole, our observation results support the hitherto proposed decomposition mechanism (unfortunately, the existence of supercooled aqueous phase was unable to be distinguished) of methane hydrates at a temperature of 240-270 K. Our results suggest the necessity of observing the microstructural changes on a nanometer scale.

Cryo-SEM has been used as a powerful tool to
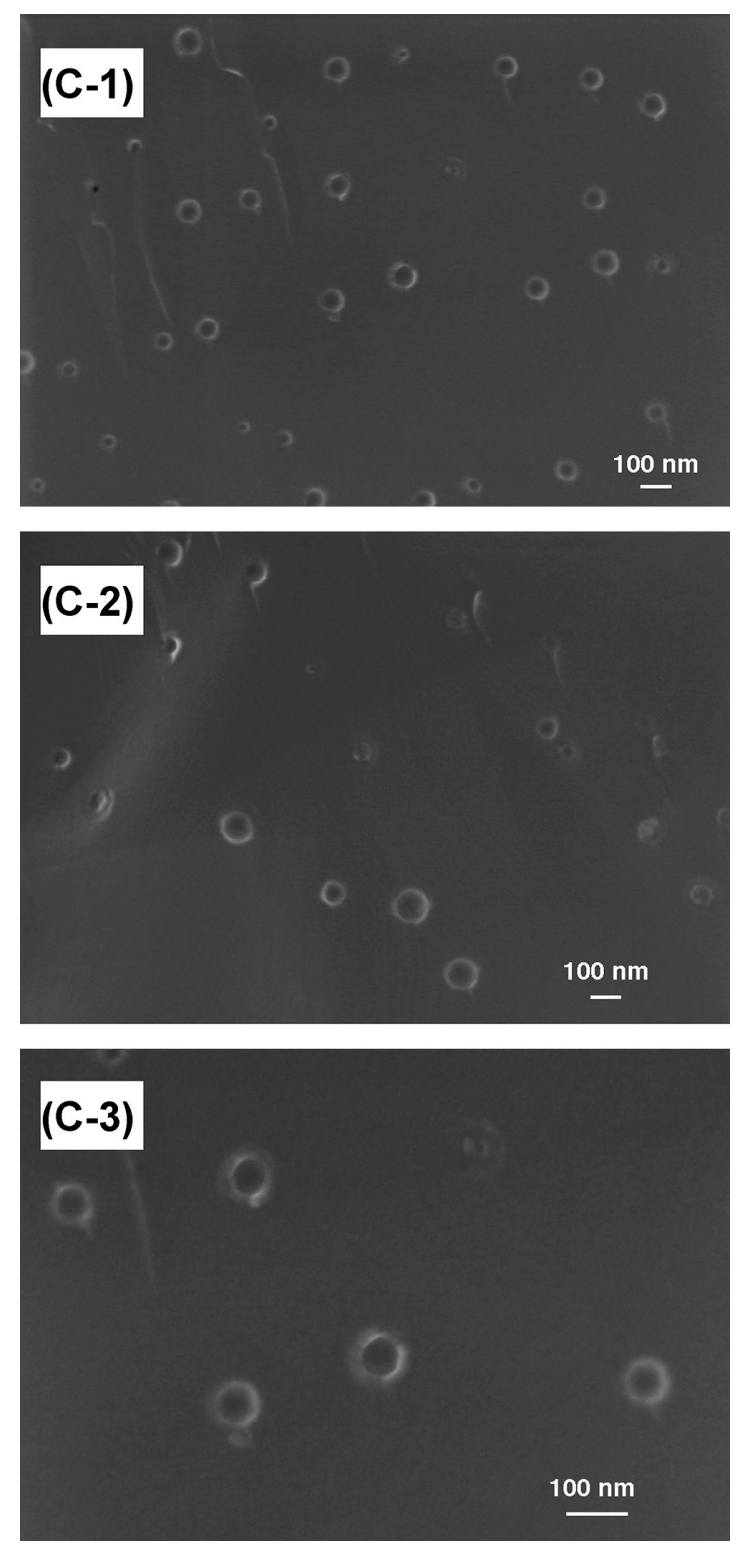

Fig. 5. SEM images of replica films reflecting the internal microstructure of residual aqueous solution after methane hydrate completely decomposed at $293 \mathrm{~K}$ (Sample "C"). The images are derived from different droplets at 50 thousands-fold (upper and middle) and 100 thousands-fold (bottom) magnifications.

directly observe the decomposition behavior. From the restriction of the circumstance inside cryo-SEM chamber, it had been difficult to recognize the microstructural change on a $10 \mathrm{~nm}$-scale or less. The freeze-fracture replica method, an indirect observation, breaks loose from the restriction inside SEM chamber and maximizes the performance of SEM observation.

\section{Acknowledgements}

One (TS) of the authors acknowledges scientific support from the Gas-Hydrate Analyzing System (GHAS) of the Division of Chemical Engineering, Department of Materials Engineering Science, Graduate School of Engineering Science, Osaka University. TS also acknowledges fruitful 
discussion in the researcher meeting " $\mathrm{H}_{2} \mathrm{O}$ Science 2017" supported by the Grant for Joint Research Program of the Institute of Low Temperature Science, Hokkaido University.

\section{References}

Falabella, B. J. and Vanpee, M. (1974): Experimental determination of gas hydrate equilibrium below the ice point. Ind. Eng. Chem. Fundam., 13, 228-231, doi: 10.1021/i160051a012.

Falenty, A., Genov, G. and Kuhs, W. F. (2007): From ice to $\mathrm{CO}_{2}$ hydrates and back-Study of nucleation and initial growth using scanning electron microscopy. In Kuhs, W. F. (ed.), Physics and Chemistry of Ice, 171-179, The Royal Society of Chemistry, Cambridge, UK, ISBN: 9780854043507.

Falenty, A., Kuhs, W. F., Glockzin, M. and Rehder, G. (2014): "Selfpreservation" of $\mathrm{CH}_{4}$ hydrates for gas transport technology: pressure-temperature dependence and ice microstructures. Energy Fuels, 28, 6275-6283, doi: 10.1021/ef501409g.

Fujimoto, A. (2017): Mesoscopic structure analysis using the freeze fracture replica method (in Japanese). Fine Chemical, 46, 28-36.

Gudmundsson, J. S. and Børrehaug, A. (1996): Frozen hydrate for transport of natural gas. Proceedings of the 2nd International Conference of Natural Gas Hydrates, 415-422, Toulouse, France.

Hirokawa, N., Ueda, M. and Harano, Y. (1994): Polymorphic transition of solid-fats dispersed systems-its characterization by a novel method and scanning electron microscopy observation. J. Cryst. Growth, 141, 200-208, doi: 10.1016/0022-0248(94)90113-9.

Ishizuka, S., Kimura, Y., Yokoi, S., Yamazaki, T., Sato, R. and Hama, T. (2017): Self-assembly of $\mathrm{MoO}_{3}$ needles in gas current for cubic formation pathway. Nanoscale, 9, 1010910116, doi: 10.1039/c7nr02613g.

Kuhs, W. F., Genov, G., Staykova, D. K. and Hansen, T. (2004): Ice perfection and onset of anomalous preservation of gas hydrates. Phys. Chem. Chem. Phys., 6, 4917-4920, doi: 10.1039/b412866d.

Kuhs, W. F., Klapproth, A., Gotthardt, F., Techmer, K. and Heinrichs, T. (2000): The formation of meso- and macroporous gas hydrates. Geophys. Res. Lett., 27, 2929-2932, doi: 10.1029/2000GL006112.

Leroy, V. and Norisuye, T. (2016): Investigating the existence of bulk nanobubbles with ultrasound. ChemPhysChem, 17, 2787-2790, doi: 10.1002/cphc.201600576

Machida, H., Sugahara, T. and Hirasawa, I. (2017): Relationship between supercooling stability and solution structure in sodium acetate aqueous solution. J. Cryst. Growth, 475, 295299, doi: 10.1016/j.jcrysgro.2017.07.006.

Makogon, T. Y. and Sloan, E. D. (1994): Phase equilibrium for methane hydrate from 190 to 262 K. J. Chem. Eng. Data, 39 351-353, doi: 10.1021/je00014a035.

Mel'nikov, V. P., Nesterov, A. N. and Reshetnikov, A. M. (2003): Mechanism of gas hydrate decomposition at a pressure of 0.1 MPa. Dokl. Earth Sci., 389A, 455-458.

Melnikov, V. P., Nesterov, A. N., Reshetnikov, A. M. and Zavodovsky, A. G. (2009): Evidence of liquid water formation during methane hydrates dissociation below the ice point. Chem. Eng. Sci., 64, 1160-1166, doi: 10.1016/j.ces.2008.10.067.

Mimachi H., Takahashi, M., Takeya, S., Gotoh, Y., Yoneyama, A., Hyodo, K., Takeda, T. and Murayama, T. (2015): Effect of long-term storage and thermal history on the gas content of natural gas hydrate pellets under ambient pressure. Energy Fuels, 29, 4827-4834, doi: 10.1021/acs.energyfuels.5b00832.

Murakami, M., Tanaka, A. and Ohgaki, K. (1997): Preparation of replica film using mixed hydrocarbon plasma (in Japanese). Appl. Plasma Sci., 5, 90-93.

Ohgaki, K., Hirokawa, N. and Ueda, M. (1992): Heterogeneity in aqueous solutions: electron microscopy of citric acid solutions. Chem. Eng. Sci., 47, 1891-1823, doi: 10.1016/00092509(92)80300-2

Ohgaki, K., Makihara, Y., Morishita, M., Ueda, M. and Hirokawa, N (1991): Solute clusters in aqueous citric acid solutions. Chem. Eng. Sci., 46, 3283-3287, doi: 10.1016/0009-2509(91)85029-W.

Ohgaki, K., Khanh, N. Q., Joden, Y., Tsuji, A. and Nakagawa, T. (2010): Physicochemical approach to nanobubble solutions. Chem. Eng. Sci., 65, 1296-1300, doi: 10.1016/j.ces.2009.10.003.

Ohno, H., Oyabu, I., Iizuka, Y., Hondoh, T., Narita, H. and Nagao, J. (2011): Dissociation Behavior of $\mathrm{C}_{2} \mathrm{H}_{6}$ hydrate at temperatures below the ice point: melting to liquid water followed by ice nucleation. J. Phys. Chem. A, 115, 8889-8894, doi: 10.1021/ jp204157w.

Rehder, G., Eckl, R., Elfgen, M., Falenty, A., Hamann, R., Kähler, N., Kuhs, W. F., Osterkamp, H. and Windmeier, C. (2012): Methane hydrate pellet transport using the self-preservation effect: a techno-economic analysis. Energies, 5, 2499-2523, doi: 10.3390/en5072499

Sato, H., Sakamoto, H., Ogino, S., Mimachi, H., Kinoshita, T., Iwasaki, T., Sano, K. and Ohgaki, K. (2013): Self-preservation of methane hydrate revealed immediately below the eutectic temperature of the mother electrolyte solution. Chem. Eng. Sci., 91, 86-89, doi: 10.1016/j.ces.2013.01.014.

Sato, H., Tsuji, T., Nakamura, T., Uesugi, K., Kinoshita, T., Takahashi, M., Mimachi, H., Iwasaki, T. and Ohgaki, K. (2009): Preservation of methane hydrates prepared from dilute electrolyte solutions. Int. J. Chem. Eng., 2009, 843274-1-5, doi:10.1155/2009/843274.

Shirota, H., Aya, I., Namie, S., Bollavaram, P., Turner, D. and Sloan E. D. (2002): Measurement of methane hydrate dissociation for application to natural gas storage and transportation. Proceedings of the 4th International Conference of Gas Hydrates, 972-977, Yokohama, Japan.

Sloan, E. D. and Koh, C. A. (2008): Clathrate Hydrates of Natural Gases, $3 r d$ ed. Taylor \& Francis-CRC Press. ISBN: 9780849390784.

Stern, L. A., Circone, S., Kirby, S. H. and Durham, W. B. (2001): Anomolous preservation of pure methane hydrate at $1 \mathrm{~atm}$. J. Phys. Chem. B, 105, 1756-1762, doi: 10.1021/jp003061s.

Sugahara, T., Makino, T. and Ohgaki, K. (2003): Isothermal phase equilibria for the methane + ethylene mixed gas hydrate system. Fluid Phase Equilib., 206, 117-126, doi: 10.1016/ S0378-3812(02)00313-8.

Takaoki, T., Iwasaki, T., Katoh, Y., Arai, T. and Horiguchi, K. (2002): Use of hydrate pellets for transportation of natural gas-I, advantage of pellet form of natural gas hydrate in sea transportation. Proceedings of the 4th International Conference on Gas Hydrates, 982-986, Yokohama, Japan.

Takeya, K., Nango, K., Sugahara, T., Ohgaki, K. and Tani, A. (2005): Activation energy of methyl radical decay in methane hydrate. J. Phys. Chem. B, 109, 21086-21088, doi: 10.1021/ jp054028e.

Takeya, S. and Ripmeester, J. A. (2008): Dissociation behavior of clathrate hydrates to ice and dependence on guest molecules. Angew. Chem., Int. Ed., 47, 1276-1279, doi: 10.1002/anie.200703718.

Takeya, S., Shimada, W., Kamata, Y., Ebinuma, T., Uchida, T., Nagao, J. and Narita, H. (2001): In situ X-ray diffraction measurements of the self-preservation effect of $\mathrm{CH}_{4}$ hydrate. J. Phys. Chem. A, 105, 9756-9759, doi: 10.1021/jp011435r.

Takeya, S., Yoneyama, A., Ueda, K., Hyodo, K., Takeda, T., Mimachi, H., Takahashi, M., Iwasaki, T., Sano, K., Yamawaki, H. and Gotoh, Y. (2011): Nondestructive imaging of anomalously preserved methane clathrate hydrate by phase contrast X-ray imaging. J. Phys. Chem. C, 115, 16193-16199, doi: 10.1021/jp202569r.

Uchida, T., Oshita, S., Ohmori, M., Tsuno, T., Soejima, K., Shinozaki, S., Take, Y. and Mitsuda, K. (2011a): Transmission electron microscopic observations of nanobubbles and their capture of impurities in wastewater. Nanoscale Res. Lett., 6, 295-1-9, doi: 10.1186/1556-276X-6-295.

Uchida, T., Sakurai, T. and Hondoh, T. (2011b): Ice-shielding models for self-preservation of gas hydrates. J. Chem. 
Chem. Eng., 5, 691-705.

Uchida, T., Yamazaki, K. and Gohara, K. (2016a): Generation of micro- and nano-bubbles in water by dissociation of gas hydrates. Korean J. Chem. Eng., 33, 1749-1755, doi: 10.1007/ s11814-016-0032-7.

Uchida, T., Yamazaki, K. and Gohara, K. (2016b): Gas nanobubbles as nucleation acceleration in the gas-hydrate memory effect. J. Phys. Chem. C, 120, 26620-26629, doi: 10.1021/acs. jpcc.6 b07995.

Ueda, M., Hirokawa, N., Harano, Y., Moritoki, M. and Ohgaki, K. (1995): Change in microstructure of an aqueous citric acid solution under crystallization. J. Cryst. Growth, 156, 261-266, doi: 10.1016/0022-0248(95)00298-7.

Yakushev, V. S. and Istomin, V. A. (1992): Gas-hydrates self- preservation effect. In Maeno, N. and Hondoh, T. (eds.), Physics and Chemistry of Ice. Hokkaido University Press, 136-140, ISBN: 978-4-8329-0261-9.

Yamazaki, T., Kimura, Y., Vekilov, P. G., Furukawa, E., Shirai, M. Matsumoto, H., van Driessche, A. E. S. and Tsukamoto, K. (2017): Two types of amorphous protein particles facilitate crystal nucleation. Proc. Natl. Acad. Sci. U. S. A., 114, 21542159, doi: 10.1073/pnas.1606948114.

Zhong, J.-R., Zeng, X.-Y., Zhuo, F.-H., Ran, Q.-D., Sun, C.-Y., Zhong, R.-Q., Yang, L.-Y., Chen, G.-J. and Koh, C. A. (2016): Selfpreservation and structural transition of gas hydrates during dissociation below the ice point: an in situ study using Raman spectroscopy. Sci. Rep., 6, 38855-1-13, doi: 10.1038/srep38855. 